\title{
Peptidylarginine deiminase IV (PADI4) is not essential for cell-autonomous HSC maintenance and normal haematopoiesis
}

\author{
Christine Young ${ }^{1,2}$, John R. Russell ${ }^{1}$, Hannah Lawson ${ }^{2,3}$, Christopher Mapperley $^{2,3}$, \\ Kamil R. Kranc ${ }^{2,3,{ }^{*}}$ and Maria A. Christophorou ${ }^{1,2,4^{*}}$ \\ ${ }^{1}$ MRC Human Genetics Unit, The Institute of Genetics and Molecular Medicine, University of \\ Edinburgh, Edinburgh EH4 2XU, United Kingdom \\ ${ }^{2}$ Centre for Regenerative Medicine, University of Edinburgh, Edinburgh, United Kingdom \\ ${ }^{3}$ Laboratory of Haematopoietic Stem Cell \& Leukaemia Biology, Centre for Haemato- \\ Oncology, Barts Cancer Institute, Queen Mary University of London, London EC1M 6BQ, \\ United Kingdom \\ ${ }^{4}$ Babraham Institute, Cambridge CB22 3AT, United Kingdom
}

*Correspondence to: Maria A. Christophorou (maria.christophorou@babraham.ac.uk) and Kamil R. Kranc (kamil.kranc@qmul.ac.uk)

\section{Key Points}

- PADI4 is dispensable for steady-state and post-transplantation haematopoiesis

- HSCs do not require intrinsic PADI4 activity to respond to haematopoietic injury

- PADI4 deficiency does not lead to premature HSC ageing or exhaustion

\begin{abstract}
Peptidylarginine deiminases (PADIs, or PADs) are emerging as key regulators of human physiology and pathophysiology. The nuclear deiminase PADI4 regulates embryonic stem cell pluripotency, however its role in adult stem cells is unknown. PADI4 is expressed most highly in the bone marrow (BM), where it is found as part of a self-renewal-associated gene signature and shown to modulate the function of critical transcriptional regulators such as Tal1 and c-Myc, suggesting that it regulates haematopoietic development or regeneration. We investigated the functional significance of PADI4 in haematopoietic stem cell (HSC) biology and normal haematopoiesis. We employed two conditional mouse models of tissue-specific Padi4 ablation, where Padi4 was completely deleted either after the emergence of HSCs, or acutely in the BM of adult mice. We found that loss of PADI4 does not significantly affect HSC self-renewal or differentiation potential upon injury or serial transplantation, nor does it lead to exhaustion or premature ageing of HSCs. Thus, surprisingly, PADI4 is dispensable for cell-autonomous HSC maintenance, differentiation and haematopoietic regeneration. This work has important implications for the clinical use of PADI4 inhibitors as therapeutic agents in autoimmunity and cancer.
\end{abstract}




\section{Introduction}

Haematopoietic stem cells (HSCs) possess self-renewal capacity and multi-lineage differentiation potential, and are therefore able to replenish all blood cell lineages, sustaining normal and post-injury haematopoiesis. In addition to transcription factors, which directly facilitate or inhibit gene transcription, one central mechanism involved in stem cell fate decisions is the modulation of expression of stem cell and differentiation genes achieved via epigenetic mechanisms such as histone modifications. Indeed, several studies have shown that histone-modifying enzymes are essential for normal haematopoiesis is, $^{1,3,4,5,6,7}$.

Peptidylarginine deiminase (PADI) enzymes catalyze citrullination, the posttranslational conversion of arginine residues within a protein to the non-coded amino acid citrulline. The five PADI family members are structurally similar and likely to operate via common regulatory mechanisms ${ }^{8,9}$, but they show varying tissue distributions and sub-cellular localisations, suggesting that they have specific organismal roles. They have been shown to regulate fundamental molecular and cellular processes such as gene expression, chromatin compaction, nerve myelination, the innate immune response and pluripotency ${ }^{10,11,12,13,14,15,16,17}$, while lack of PADI activity leads to infertility and defects in neurodevelopment and embryo development ${ }^{11,18,19}$. PADI4 citrullinates core and linker histone proteins and has wellestablished roles in the regulation of gene transcription and chromatin compaction. We previously showed that PADI4 mediates the establishment of pluripotency ${ }^{11}$, however it is unknown whether it has a role in adult stem cells. Out of all mammalian tissues, Padi4 is most highly expressed in the bone marrow (BM) and is one of the top 50 genes associated with self-renewal, as determined by the fact that it is downregulated upon differentiation to all multi-lineage progenitors, but up-regulated again in leukaemia stem cells ${ }^{20}$. More recent studies showed that haematopoietic multipotent progenitor cells from Padi4-null mice exhibit increased proliferation and that PADI4 is a co-activator of Tal1, a critical transcriptional regulator in the haematopoietic system ${ }^{21,22}$. Taken together, these findings suggest that PADI4 functions in the regulation of haematopoiesis.

To understand the role of PADI4 in normal haematopoiesis, HSC maintenance, haematopoietic regeneration and ageing, we constitutively and inducibly deleted Padi4 from the haematopoietic system. We demonstrate that HSCs do not require PADI4 to self-renew, sustain long-term multilineage haematopoiesis or respond to haematopoietic injury. Moreover, by investigating long-term consequences of Padi4 deletion, we show that Padi4 loss does not lead to HSC exhaustion or premature ageing.

\section{Results and Discussion}

To determine the functional significance of PADI4 in steady-state haematopoiesis and HSC self-renewal, we deleted Padi4 specifically from the haematopoietic system using the Vav-iCre system. Vav-iCre mice ${ }^{23}$ constitutively express the codonimproved Cre (iCre) ${ }^{24}$ driven by the Vav regulatory elements ${ }^{25}$, resulting in haematopoietic-specific gene deletion shortly after the emergence of definitive $\mathrm{HSCs}^{26}$ and ensuring recombination in all $\mathrm{HSCs}^{27,28}$. We bred these mice to Padi4 ${ }^{\text {fl/fl }}$ mice $^{29}$, in which Padi4 exons 9 and 10 are flanked by loxP sites. These exons contain aspartate 352 , which is part of the active site, as well as four additional residues (Q351, E353, E355, D371), which are essential for $\mathrm{Ca}^{2+}$ binding and activation of the enzyme ${ }^{8}$. The resulting Padi4 ${ }^{\text {flffl }} ; \mathrm{Vav}-\mathrm{iCre}$ mice (referred to as 
Padi4 $^{\mathrm{CKO}}$ hereafter) completely lack PADI4 protein expression in the BM (Figure 1A). These mice were compared to Padi4 ${ }^{\mathrm{fl} / \mathrm{fl}}$ mice (referred to as Padi4 ${ }^{\mathrm{CTL}}$ ) in all subsequent analyses. Padi4 ${ }^{\mathrm{CKO}}$ and Padi4 ${ }^{\mathrm{CTL}}$ mice showed normal Mendelian distribution, had comparable survival and did not display any obvious defects. To enumerate cells at different levels of the haematopoietic differentiation hierarchy, we next carried out immunophenotypic analyses of Padi4 ${ }^{\mathrm{CKO}}$ mice. In agreement with a previous report ${ }^{21}$, Padi4 ${ }^{\mathrm{CKO}}$ mice had increased numbers of $\mathrm{Lin}^{-} \mathrm{Sca}-1^{+} \mathrm{C}-\mathrm{Kit}^{+}$(LSK) cells but similar numbers of total white blood cells (WBC) and lineage restricted myeloid and erythroid of $\mathrm{Lin}^{-} \mathrm{Sca}-1^{-} \mathrm{C}-\mathrm{Kit}^{+}$(LK) progenitor cells compared to Padi4 ${ }^{\mathrm{CTL}}$ mice (Figure 1B). Further analysis of the LSK compartment showed normal numbers of $\mathrm{LSKCD}^{-} 8^{-} \mathrm{CD} 150^{+} \mathrm{HSCs}$, LSKCD48 ${ }^{-} \mathrm{CD} 150^{-}$multipotent progenitors (MPPs), $\mathrm{LKSCD} 48^{+} \mathrm{CD} 150^{+}$primitive haematopoietic progenitors (HPC-2) and an increase in LSKCD $48^{+}$CD $150^{-}$haematopoietic progenitor cell-1 (HPC-1) population in Padi4 ${ }^{\text {CKO }}$ mice compared to Padi4 ${ }^{\mathrm{CTL}}$ mice (Figure 1C). We observed an increase in common lymphoid progenitors ( $\mathrm{Lin}^{-} \mathrm{C}-\mathrm{Kit}^{\mathrm{lo}} \mathrm{Sca}{ }^{\mathrm{lo}} \mathrm{IL} 7 \mathrm{Ra}^{+} \mathrm{cells}$ ) in Padi4 ${ }^{\mathrm{CKO}}$ mice compared to Padi4 $^{\mathrm{CTL}}$ mice (Figure 1D). However, the numbers of myeloid and erythroid progenitors, CD11 $\mathrm{b}^{+} \mathrm{Gr} 1^{-}$and $\mathrm{CD} 11 \mathrm{~b}^{+} \mathrm{Gr} 1^{+}$differentiated myeloid cells, CD19 ${ }^{+} \mathrm{B}$ cells and Ter1 $19^{+}$erythroid cells, were comparable in the BM between Padi4 ${ }^{\mathrm{CKO}}$ and Padi4 $^{\mathrm{CTL}}$ mice (Figure 1E). These results were mirrored in in vitro colony forming cell (CFC) assays where there was no difference in colony counts between the two genotypes (Figure 1F). In addition, numbers of thymic T-cells were unaffected (Figure 1G). Analysis of peripheral blood (PB) showed that the numbers of circulating blood cells and haemoglobin parameters were completely unaffected by Padi4 deletion (Supplementary Figure 1A). Analysis of the spleens showed a modest increase in differentiated cells in Padi4 ${ }^{\mathrm{CKO}}$ mice with an overall increase in WBC counts, indicating extramedullary haematopoiesis (Figure $1 \mathbf{H}$ ). In conclusion, despite mild extramedullary haematopoiesis, Padi4 deletion has no major impact on BM steady-state haematopoiesis.

To assess the requirement for Padi4 in HSC maintenance, we performed competitive HSC transplantation assays. CD $45.2^{+}$LSKCD $48^{-}$CD $150^{+}$HSCs sorted from Padi4 ${ }^{\text {CKO }}$ and control (Padi4 ${ }^{\mathrm{CTL}}$ ) mice were competitively transplanted into lethally irradiated wild-type syngeneic $C D 45.1^{+} / C D 45.2^{+}$recipients (Figure 11). Peripheral blood analysis showed no difference in $\mathrm{CD} 45.2^{+}$donor-derived chimerism in primary recipients of the Padi4 ${ }^{\mathrm{CKO}}$ HSCs when compared to recipients of Padi4 ${ }^{\mathrm{CTL}}$ HSCs (Supplementary Figure 2A). BM analysis at 16 weeks post-transplant showed that HSCs of both genotypes efficiently reconstituted long-term multilineage haematopoiesis, while donor-derived cells contributed equally to BM HSC and primitive cell compartments of the primary recipient mice (Figure $1 \mathbf{J}$ ). No difference in CD $45.2^{+}$cell engraftment was found in the spleen of recipient mice and both Padi4 ${ }^{\mathrm{CTL}}$ and Padi ${ }^{\mathrm{CKO}}$ donor derived cells contributed equally to differentiated cell populations in the spleen (Figure 1K). Moreover, Padi4 ${ }^{\mathrm{CKO}}$ LSK cells sustained long-term BM reconstitution in secondary recipients comparably to Padi4 ${ }^{\mathrm{CTL}}$ LSK cells (Figure 1L), while equal engraftment of CD $45.2^{+}$cell engraftment was observed in spleen (Figure $1 \mathrm{~L})$ of the secondary recipients. In addition, no difference in $\mathrm{CD} 45.2^{+}$cell engraftment was found in PB (Supplementary Figure 2B). These experiments revealed that HSCs do not require Padi4 to self-renew and sustain long-term multi-lineage haematopoiesis upon transplantation.

Given that Vav-iCre recombines in the embryo soon after the emergence of definitive HSCs, it is possible that that deletion of Padi4 during haematopoietic development is compensated for by the activity of another member of the peptidylarginine deiminase family. Indeed, although PADI4 is the only predominantly nuclear member of the PADI family, PADI2 and PADI1 have also been shown to act in the nucleus ${ }^{17,30,31}$ and regulate gene expression. To rule out the possibility of compensation, we examined 
HSC maintenance following acute Padi4 deletion in adult mice. We generated Padi4 $^{\text {fl/fI}} ;$ Mx1-Cre mice (referred to as Padi4 ${ }^{\mid K O}$ hereafter) in which efficient recombination in the $\mathrm{BM}$ is induced by treatment with Poly $\mathrm{I}: \mathrm{C}^{32}$. Padi4 ${ }^{\mathrm{IKO}}$ and Padi4 $^{\mathrm{CTL}}$ mice received 6 injections of $300 \mu \mathrm{g}$ Poly I:C, on every other day, and were culled and analysed 4 weeks following the final administration. We found that acute deletion of Padi4 had no effect on any bone marrow cell compartment analysed (Figure 1N). To test whether acute Padi4 deletion affects post-transplantation haematopoietic reconstitution, we transplanted CD45.2 ${ }^{+}$unfractionated BM cells from Padi4 ${ }^{\mathrm{KO}}$ or Padi4 ${ }^{\mathrm{CTL}}$ mice with support CD45.1 $1^{+} \mathrm{BM}$ cells to lethally irradiated recipient mice. Following efficient $C D 45.2^{+}$cell engraftment (8 weeks post transplantation), the mice received 6 doses of Poly I:C resulting in efficient Padi4 deletion in donor-derived CD45.2 $2^{+}$cells (Figure 10 and Supplementary Figure 3A). The contribution of CD $45.2^{+}$cells to the PB of the recipients was quantified at 4,8 , 12, 18 and 22 weeks post transplantation and no differences were observed (Supplementary Figure 3B). The donor-derived contribution of CD45.2 $2^{+}$cells to BM cell compartments of the recipients, including total WBC, LSK, LK and HSCs of the recipients was similar regardless of the genotype of transplanted CD45. $2^{+}$cells, as was the CD $45.2^{+}$cell contribution to differentiated cell lineages in the BM (Figure 1P). Therefore, compensation from another of the PADI family members can be excluded.

To test the role of Padi4 in HSC regenerative capacity upon haematopoietic injury, we treated adult (8-12 week) Padi4 ${ }^{\mathrm{CKO}}$ and Padi4 ${ }^{\mathrm{CTL}}$ mice with 5-fluorouracil (5-FU). Mice received 3 injections of 5-FU 10 days apart and BM was analysed 10 days following the final dose (Figure 2A). We observed no difference in numbers of HSCs, LSK, LK cell compartments or differentiated cells in the BM of Padi4 ${ }^{\mathrm{CKO}}$ mice compared to Padi4 ${ }^{\mathrm{CTL}}$ mice (Figure 2B and Supplementary Figure 4). Therefore, PADI4 is dispensable for the ability of HSCs to respond to haematopoietic stress.

To investigate the long-term effects of Padi4 deletion in the haematopoietic system, we carried out immunophenotypic analyses of Padi4 ${ }^{\text {CKO }}$ mice aged up to 1 year, as well as BM reconstitution experiments using HSCs from these aged mice (Figure 2C,D). Analysis of BM and spleens of 1 year-old Padi4 ${ }^{\mathrm{CKO}}$ mice and Padi4 ${ }^{\mathrm{CTL}}$ mice showed no difference in cell counts of total WBC, primitive LSK compartments, LK progenitor populations or differentiated cell populations (Figure $2 \mathrm{C}$ ). In addition, in vitro CFC assays using aged BM from Padi4 ${ }^{\mathrm{CKO}}$ and Padi4 ${ }^{\mathrm{CTL}}$ mice also showed no difference in CFC colony count between the genotypes (Figure 2C). In fact, the differences observed in young mice (Figure 1B,C,H) were not observed upon ageing. To assess the self-renewal potential of aged Padi4 ${ }^{\mathrm{CKO}} \mathrm{HSCs}$, we transplanted sorted HSCs from 1-year old Padi4 ${ }^{\mathrm{CKO}}$ and Padi4 ${ }^{\mathrm{CTL}}$ mice into primary recipients and analysed the bone marrow of the recipients at 36 weeks post-transplantation. Mice transplanted with Padi4 ${ }^{\mathrm{CKO}} \mathrm{HSCs}$ showed a small decrease in the contribution of donor derived CD45.2 $2^{+}$cells to the LK and HPC1 progenitor populations as well as a decrease in differentiated granulocytes (Figure 2D). No differences in the ability of Padi4 ${ }^{\mathrm{CKO}}$ HSCs to contribute to spleen or peripheral blood cells was found (Figure 2D and Supplementary Figure 5). Taken together, these results show that PADI4 is dispensable for long-term cell-autonomous HSC maintenance and normal haematopoiesis.

This study demonstrates that PADI4 is not required for steady-state haematopoiesis, long-term self-renewal of HSCs, efficient reconstitution of multi-lineage haematopoiesis in serial transplantation assays or response of HSCs to haematopoietic injury. This is surprising in the face of evidence that arginine methyltransferases, which catalyse protein arginine methylation, a modification that is antagonistic to citrullination ${ }^{33,34}$, have clear roles in the regulation of haematopoiesis ${ }^{67}$. PADI4 is expressed in haematopoietic and leukaemia stem cells, 
but not in committed haematopoietic progenitors ${ }^{20}$ and was shown to act as a coactivator of Tal1, a key transcriptional regulator in haematopoiesis, specifically by counteracting histone arginine methylation ${ }^{22}$. A previous study conducted using Padi4-null mice ${ }^{21}$ suggested that PADI4 regulates the proliferation of multipotent stem cells in the BM, as such mice showed increased numbers of LSK cells. Our experiments using haematopoiesis-specific deletion of Padi4 replicate this phenotype but our comprehensive analyses of normal haematopoiesis and HSC maintenance under steady-state conditions and upon stress show that Padi4 deletion does not affect any aspects of haematopoiesis, despite a transient increase in some of the multipotent progenitor cell populations. We therefore conclude that HSCs do not require intrinsic PADI4 activity for their cell-autonomous functions. As significant efforts are underway to generate potent and specific inhibitors of PADI4 as a therapeutic approach against autoimmune disorders and $\operatorname{cancer}^{35}$, this study indicates that these can be used systemically without adverse effects to the haematopoietic system. 


\section{Materials and Methods}

Mice. All experiments on animals were performed under UK Home Office authorisation. All mice were of C57BL/6 genetic background. Padi4 $4^{\mathrm{fl} / \mathrm{fl}} \mathrm{mice}^{29}$ were a kind gift from the Mowen lab. Vav-iCre ${ }^{23}, \mathrm{M} 1-\mathrm{Cre}^{36}$, have been described previously ${ }^{37}$. All transgenic and knockout mice were CD $45.2^{+}$. Congenic recipient mice were CD $45.1^{+} / C D 45.2^{+}$. Sex-matched 8 to 12 week-old mice were used throughout.

Flow cytometry. All BM cells were prepared and analyzed as described previously ${ }^{37-41}$. BM cells were isolated by crushing tibias and femurs using a pestle and mortar. Cell suspensions were passed through a $70 \mu \mathrm{m}$ strainer. PB was collected in EDTA coated microvettes. Spleen and thymus were homogenised and passed through a cell strainer. Single cell suspensions were incubated with Fc block and then stained with antibodies. For HSC cell analyses, unfractionated BM cells were stained with a lineage marker cocktail containing biotin-conjugated anti-CD4, anti-CD5, anti-CD8a, anti-CD11b, anti-B220, anti-Gr-1 and anti-Ter119 antibodies together with APC-conjugated anti-C-Kit, FITC-conjugated anti-Sca-1, PE-conjugated anti-CD48 and PE-Cy7-conjugated anti-CD150 antibodies. Biotin-conjugated antibodies were then stained with Pacific Blue-conjugated streptavidin. For panlineage progenitor cell staining, cells were stained with the lineage marker cocktail described above together with APC-conjugated anti-c-kit, PE-Cy7-conjugated antiSca-1, BV-421-conjugated anti-CD127, FITC-conjugated anti-CD34, PE-conjugated anti-CD135 and APC-Cy7-conjugated anti-CD16/32. For myeloid/T lymphoid restricted progenitors, cells were stained with a lineage marker cocktail containing biotin-conjugated anti-CD4, anti-CD5, anti-CD8a, anti-Mac-1, anti-B220, anti-CD19 and anti-Gr-1 together with BV-510-conjugated anti-c-kit, Pacific Blue-conjugated anti-Sca-1, PE-Cy7-conjugated anti-CD150, APC-Cy7-conjugated anti-CD16/32, APC-conjugated anti-CD41, PE-conjugated anti-CD105 and FITC-conjugated antiTer119. Biotin-conjugated antibodies were then stained with PerCP-conjugated streptavidin. For analyses of differentiated cells, spleen, BM or PB cell suspensions were stained with APC-Cy7-conjugated anti-CD19 antibody for B cells; Pacific Blueconjugated anti-CD11b and PE-Cy7-conjugated anti-Gr-1 for myeloid cells; APCconjugated anti-CD8 antibodies and PE-conjugated anti-CD4 antibodies for T cell analysis (spleen and PB); FITC-conjugated anti-Ter119 and PE-conjugated antiCD71 (BM).

To distinguish CD45.2 $2^{+}$-donor derived cells in the BM and spleen of transplanted mice, BV711-conjugated anti-CD45.1 and Pacific Blue-conjugated anti-CD45.2 antibodies were used. For HSC staining in transplanted mice, the remainder of the staining was as described above. For analyses of differentiated cells in BM and spleen of transplanted mice, myeloid cells were stained with PE-conjugated antiCD11b, PE-Cy7-conjugated anti-Gr-1 and FITC-conjugated anti-Ter119 for erythroid cells. B Lymphoid cells were stained with APC-Cy7-conjugated anti-CD19. PB of transplanted mice was stained with FITC-conjugated anti-CD45.1, Pacific Blueconjugated anti-CD45.2, PE-conjugated anti-CD4 and-CD8a, PE-Cy7-conjugated anti-Gr-1, APC-conjugated anti-CD11b, and APC-Cy7-conjugated anti-CD19.

Flow cytometry analyses were performed using a LSRFortessa (BD). Cell sorting was performed on a FACSAria Fusion (BD).

Colony forming cells (CFC) assays. CFC assays were carried out using MethoCult $^{\mathrm{TM}}$ M3434 (STEMCELL Technologies) methylcellulose medium. Two technical replicates were used per each biological replicate in each experiment. BM cells were plated for 10 days before colony types were identified and counted. 
Blood profiling. Blood was collected via cardiac puncture into an EDTA coated microvette and analysed on a Celltaq Haematology analyser (Nihon Kohden).

Syngeneic transplantation assays. CD $45.1^{+} / \mathrm{CD} 45.2^{+} \mathrm{C} 57 \mathrm{BL} / 6$ recipient mice were lethally irradiated using a split dose of $11 \mathrm{~Gy}$ (two doses of $5.5 \mathrm{~Gy}$ administered at least 4 hours apart) at an average rate of $0.58 \mathrm{~Gy} / \mathrm{min}$ using a Cesium 137

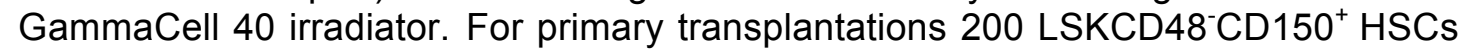
(per recipient) sorted from BM of the donor mice were mixed with 200,000 unfractionated support CD45.1 $1^{+}$wild type BM cells and transferred into lethally irradiated CD $45.1^{+} /$CD $45.2^{+}$recipients. For secondary transplantations $2,000-3,000$ CD $45.2^{+}$LSK cells sorted from BM of primary recipients were mixed with 200,000 unfractionated support CD45.1 $1^{+}$wild-type BM cells and re-transplanted. For all except ageing experiments, primary and secondary recipients were culled and analysed 16-20 weeks post transplant.

Poly I:C administration. Both Padi4 ${ }^{\mathrm{CTL}}$ and Padi4 ${ }^{\mathrm{IKO}}$ (Padi4;Mx1-Cre) transgenic and $\mathrm{CD} 45.1^{+} / \mathrm{CD} 45.2^{+} \mathrm{C} 57 \mathrm{BL} / 6$ recipient mice were injected intraperitoneally with poly I:C. Padi4 ${ }^{\mathrm{CTL}}$ and Padi4 ${ }^{\mathrm{KKO}}$ mice received 6 injections of $300 \mu \mathrm{g}$ Poly I:C, on every other day. Mice were culled and analysed 1 month following the final administration. Recipient mice received one injection every other day with $300 \mu \mathrm{g}$ Poly I:C (GE Healthcare) for a total of 6 doses starting 8 weeks after transplantation as previously described ${ }^{38,40,41}$.

5-FU administration. Both Padi4 ${ }^{C T L}$ and Padi4 ${ }^{C K O}$ transgenic mice were injected intraperitoneally with $5-\mathrm{FU}$. Mice were weighed on the day of administration and received 3 injections of $150 \mathrm{mg} / \mathrm{kg} 10$ days apart. Mice were culled and analysed 10 days following the final administration.

Western blotting. Proteins extracted from Padi4 ${ }^{C T L}$ and Padi4 ${ }^{C K O}$ were subjected to SDS-PAGE (4-20\% Mini-PROTEAN ${ }^{\circledR}$ TGX $^{\text {TM }}$ Precast gel, Biorad) and then transferred onto a nitrocellulose membrane. Membranes were blocked in 5\% BSATBST (TBS with $0.1 \%$ Tween20) and probed with anti-Padi4 (Abcam ab214810, $1: 1000, \mathrm{O} / \mathrm{N}$ at $4^{\circ} \mathrm{C}$ ) and anti-Actin (Santa Cruz, sc-1616, 1:500, O/N at $4^{\circ} \mathrm{C}$ ). After incubation with appropriate horseradish peroxidase-coupled secondary antibody, proteins were detected with SuperSignal ${ }^{\mathrm{TM}}$ West Pico PLUS Chemiluminescent Substrate (ThermoFisher Scientific) and acquired on the ImageQuant LAS (GE Healthcare Life Sciences).

Genotyping. DNA was extracted from bone marrow taken from recipient mice transplanted with Padi4 ${ }^{\mathrm{CTL}}$, Padi4 ${ }^{\mathrm{CKO}}$ or Padi4 ${ }^{\mathrm{IKO}}$ mice. PCR was performed using primers specific for Padi4 deletion. Forward primer: 5'-CAG GAG GTG TAC GTG TGC A-3'. Reverse primer: 5'-AGT CCA GCT GAC CCT GAA C-3'. Expected band sizes: Wild-type Padi4 allele: 104bp; Floxed Padi4 allele: 160bp; Knock-out Padi4 allele: $215 \mathrm{bp}$.

Statistical analysis. Statistical significance was determined using Mann-Whitney or One-Way ANOVA on Graphpad V 8 software. 


\section{References}

1. Wang, Y. C., Peterson, S. E. \& Loring, J. F. Protein post-translational modifications and regulation of pluripotency in human stem cells. Cell Research 24, 143-160 (2014).

2. Ou, X. et al. SIRT1 deficiency compromises mouse embryonic stem cell hematopoietic differentiation, and embryonic and adult hematopoiesis in the mouse. Blood 117, 440-450 (2011).

3. Thieme, S. et al. The histone demethylase UTX regulates stem cell migration and hematopoiesis. Blood 121, 2462-2473 (2013).

4. Loizou, J. I. et al. Histone Acetyltransferase Cofactor Trrap Is Essential for Maintaining the Hematopoietic Stem/Progenitor Cell Pool. J. Immunol. 183, 6422-6431 (2009).

5. Chan, R. J., Johnson, S. A., Li, Y., Yoder, M. C. \& Feng, G. S. A definitive role of Shp-2 tyrosine phosphatase in mediating embryonic stem cell differentiation and hematopoiesis. Blood 102, 2074-2080 (2003).

6. Greenblatt, S. M., Liu, F. \& Nimer, S. D. Arginine methyltransferases in normal and malignant hematopoiesis. Experimental Hematology 44, 435-441 (2016).

7. Liu, F. et al. Arginine methyltransferase PRMT5 is essential for sustaining normal adult hematopoiesis. J. Clin. Invest. 125, 3532-3544 (2015).

8. Arita, K. et al. Structural basis for Ca2+-induced activation of human PAD4. Nat. Struct. Mol. Biol. 11, 777-783 (2004).

9. Slade, D. J. et al. Protein arginine deiminase 2 binds calcium in an ordered fashion: Implications for inhibitor design. ACS Chem. Biol. 10, 1043-1053 (2015).

10. Wang, S. \& Wang, Y. Peptidylarginine deiminases in citrullination, gene regulation, health and pathogenesis. Biochimica et Biophysica Acta - Gene Regulatory Mechanisms 1829, 1126-1135 (2013).

11. Christophorou, M. A. et al. Citrullination regulates pluripotency and histone $\mathrm{H} 1$ binding to chromatin. Nature 507, 104-8 (2014).

12. Tanikawa, C. et al. Regulation of protein citrullination through p53/PADI4Network in DNA damage response. Cancer Res. 69, 8761-8769 (2009).

13. Guo, Q. \& Fast, W. Citrullination of Inhibitor of Growth 4 (ING4) by Peptidylarginine Deminase 4 (PAD4) disrupts the interaction between ING4 and p53. J. Biol. Chem. 286, 17069-17078 (2011).

14. Snijders, A. P. et al. Arginine methylation and citrullination of splicing factor proline- and glutamine-rich (SFPQ/PSF) regulates its association with mRNA. RNA 21, 347-359 (2015).

15. Stadler, S. C. et al. Dysregulation of PAD4-mediated citrullination of nuclear GSK3 activates TGF- signaling and induces epithelial-to-mesenchymal transition in breast cancer cells. Proc. Natl. Acad. Sci. 110, 11851-11856 (2013).

16. Tanikawa, C. et al. Citrullination of RGG Motifs in FET Proteins by PAD4 Regulates Protein Aggregation and ALS Susceptibility. Cell Rep. 22, 14731483 (2018).

17. Sharma, P. et al. Arginine Citrullination at the C-Terminal Domain Controls RNA Polymerase II Transcription. Mol. Cell 73, 84-96.e7 (2019).

18. Falcão, A. M. et al. PAD2-Mediated Citrullination Contributes to Efficient Oligodendrocyte Differentiation and Myelination. Cell Rep. (2019). doi:10.1016/j.celrep.2019.03.108

19. Esposito, G. et al. Peptidylarginine deiminase (PAD) 6 is essential for oocyte cytoskeletal sheet formation and female fertility. Mol. Cell. Endocrinol. (2007). doi:10.1016/j.mce.2007.05.005

20. Krivtsov, A. V. et al. Transformation from committed progenitor to leukaemia stem cell initiated by MLL-AF9. Nature 442, 818-822 (2006). 
21. Nakashima, K. et al. PAD4 regulates proliferation of multipotent haematopoietic cells by controlling c-myc expression. Nat. Commun. $\mathbf{4}$, (2013).

22. Kolodziej, S. et al. PADI4 acts as a coactivator of Tal1 by counteracting repressive histone arginine methylation. Nat. Commun. 5, (2014).

23. Jasper, de B. et al. Transgenic mice with hematopoietic and lymphoid specific expression of Cre. Eur. J. Immunol. 33, 314-325 (2003).

24. Shimshek, D. R. et al. Codon-improved Cre recombinase (iCre) expression in the mouse. Genesis 32, 19-26 (2002).

25. Ogilvy, S. et al. Promoter elements of vav drive transgene expression in vivo throughout the hematopoietic compartment. Blood 94, 1855-63 (1999).

26. Chen, M. J., Yokomizo, T., Zeigler, B. M., Dzierzak, E. \& Speck, N. A. Runx1 is required for the endothelial to haematopoietic cell transition but not thereafter. Nature 457, 887-891 (2009).

27. Buza-Vidas, N. et al. GATA3 is redundant for maintenance and self-renewal of hematopoietic stem cells. Blood 118, 1291-1293 (2011).

28. Paris, J. et al. Targeting the RNA m6A Reader YTHDF2 Selectively Compromises Cancer Stem Cells in Acute Myeloid Leukemia. Cell Stem Cell 25, 137-148.e6 (2019).

29. Hemmers, S., Teijaro, J. R., Arandjelovic, S. \& Mowen, K. A. PAD4-mediated neutrophil extracellular trap formation is not required for immunity against influenza infection. PLoS One 6, (2011).

30. Xiao, S. et al. SMARCAD1 Contributes to the Regulation of Naive Pluripotency by Interacting with Histone Citrullination. Cell Rep. 18, 3117-3128 (2017).

31. Zhang, $X$. et al. Peptidylarginine deiminase 1-catalyzed histone citrullination is essential for early embryo development. Sci. Rep. 6, (2016).

32. Kühn, R., Schwenk, F., Aguet, M. \& Rajewsky, K. Inducible gene targeting in mice. Science. 269, 1427-1429 (1995).

33. Cuthbert, G. L. et al. Histone deimination antagonizes arginine methylation. Cell 118, 545-553 (2004).

34. Wang, Y. et al. Human PAD4 regulates histone arginine methylation levels via demethylimination. Science. 306, 279-283 (2004).

35. Lewis, H. D. \& Nacht, M. IPAD or PADi - 'tablets' with therapeutic disease potential? Current Opinion in Chemical Biology 33, 169-178 (2016).

36. de Boer, J. et al. Transgenic mice with hematopoietic and lymphoid specific expression of Cre. European Journal of Immunology (2003). doi:10.1002/immu.200310005

37. Vukovic, M. et al. Hif- $1 \alpha$ and Hif-2 $\alpha$ synergize to suppress AML development but are dispensable for disease maintenance. J. Exp. Med. 212, 2223-2234 (2015).

38. Kranc, K. R. et al. Cited2 Is an Essential Regulator of Adult Hematopoietic Stem Cells. Cell Stem Cell 5, 659-665 (2009).

39. Mortensen, M. et al. The autophagy protein Atg7 is essential for hematopoietic stem cell maintenance. J. Exp. Med. (2011). doi:10.1084/jem.20101145

40. Guitart, A. V. et al. Hif-2 $\alpha$ is not essential for cell-autonomous hematopoietic stem cell maintenance. Blood 122, 1741-1745 (2013).

41. Guitart, A. V. et al. Fumarate hydratase is a critical metabolic regulator of hematopoietic stem cell functions. J. Exp. Med. 214, 719-735 (2017). 


\section{Figure Legends}

Figure 1. Haematopoiesis-specific deletion of PADI4 has no major impact on steady-state haematopoiesis or BM reconstitution potential following serial transplantations (A) Immunoblot analysis of mouse PADI4 in total BM extracts from Padi4 $^{\mathrm{CTL}}$ and Padi4 ${ }^{\mathrm{CKO}}$ mice. Actin presented as a loading control. (B-G) Immunophenotypic analysis of bone marrow from 8-12 week old mice; total number of (B) WBC, LSK, and LK cells (C) HSC, MPP, HPC-1 and HPC-2 cells. Padi4 ${ }^{\mathrm{CTL}}, \mathrm{n}=$ 9; Padi4 ${ }^{\mathrm{CKO}}, \mathrm{n}=$ 9. (D,E) Total number of lymphoid, myeloid and erythroid progenitor cells. (D) CLP, (E) CMP, GMP, MEP, Pre-GMP, Pre-MegE, MkP, Pre-CFU, CFU-E, Pro-Ery and differentiated cell populations (Granulocytes, Monocytes, Erythroid and B cells). Padi4 ${ }^{\mathrm{CTL}}, \mathrm{n}=9$; Padi4 ${ }^{\mathrm{CKO}}, \mathrm{n}=9$. (F) CFC assay with $\mathrm{BM}$ cells. Padi4 ${ }^{\mathrm{CTL}}, \mathrm{n}=$ 5; Padi4 ${ }^{\mathrm{CKO}}, \mathrm{n}=6$. (G) Total number of thymic T cells. Padi4 ${ }^{\mathrm{CTL}}, \mathrm{n}=9$; Padi4 ${ }^{\mathrm{CKO}}, \mathrm{n}=$ 9. (H) Immunophenotypic analysis of spleen from 8-12 week old mice; total number of WBC, T cells and differentiated cell populations (Granulocytes, Monocytes, Erythroid and $\mathrm{B}$ cells). Padi4 ${ }^{\mathrm{CTL}}, \mathrm{n}=9 ;$ Padi4 $^{\mathrm{CKO}}, \mathrm{n}=9$. (I) Experimental design for BM transplantation experiments. 200 CD45.2+ BM HSCs from C57BL/6 Padi4 ${ }^{\mathrm{CTL}}$ or Padi4 ${ }^{\mathrm{CKO}}$ mice were transplanted into primary recipient mice and monitored for 16 weeks. Following this, a cohort of mice were sacrificed for analysis at 16 weeks post transplantation and bone marrow was transplanted to secondary recipients. (J) Percentage of donor-derived CD45.2+ cells in total BM, LSK, LK, HSC, MPP, HPC-1, HPC-2 and differentiated cell populations (Granulocytes, Monocytes, Erythroid and B cells). Padi4 ${ }^{\mathrm{CTL}}, \mathrm{n}=14$; Padi4 ${ }^{\mathrm{CKO}}, \mathrm{n}=13$. (K) Contribution of donor-derived CD45.2+ cell population to total spleen WBC count and differentiated cell populations of primary recipients. Padi4 ${ }^{\mathrm{CTL}}, \mathrm{n}=6$; Padi ${ }^{\mathrm{CKO}}, \mathrm{n}=6$. (L-M) Secondary recipient mice were transplanted with 3000 sorted CD45.2+ BM LSK cells from primary recipients sacrificed at 16 weeks. (L) Percentage of donor-derived CD45.2+ cells in total BM, LSK, LK, HSC, MPP, HPC-1, HPC-1 and differentiated cell lineages (Granulocytes, Monocytes, Erythroid and B cells). Padi4 ${ }^{\mathrm{CTL}}, \mathrm{n}=19 ;$ Padi4 $^{\mathrm{CKO}}, \mathrm{n}=19.2-4$ donors were used per genotype. (M) Contribution of donor-derived CD45.2+ cell population to spleen WBC and differentiated cells of secondary recipients. Padi4 ${ }^{\mathrm{CTL}}, \mathrm{n}=19$; Padi4 ${ }^{\mathrm{CKO}}, \mathrm{n}=19$. (N-P). Acute deletion of Padi4 in adult HSCs. Padi4 ${ }^{\mathrm{CTL}}$ and Padi4l ${ }^{\mathrm{KO}}$ mice received $6 \times$ IP injection of Poly I:C to induce deletion of Padi4. (N) Immunophenotypic analysis performed 4 weeks following the final injection. Total number of: WBC, LSK, LK, HSC, MPP, HPC-1 and HPC-2 cells; myeloid, erythroid and lymphoid progenitor cells: GMP, MEP, CMP, CLP Pre-GMP, Pre-MegE, MkP, Pre-CFU, CFU-E, Pro-Ery; differentiated granulocytes, monocytes, B cells and erythroid cells in the BM. $n=5-8$ per genotype. (O) Schematic of experimental procedure for transplantation of Padi4 ${ }^{\mathrm{CTL}}$ and Padi4 ${ }^{\mathrm{KOO}} \mathrm{BM}$ cells. $2 \times 10^{5}$ unfractionated CD45.2+ BM cells from untreated Padi4 ${ }^{\mathrm{CTL}}$ and Padi4 ${ }^{\mathrm{IKO}}$ C57BL/6 (812 wk old) mice were mixed with $2 \times 10^{5}$ CD45.1+ WT BM cells and transplanted into lethally irradiated CD45.1+/CD45.2+ recipients. $8 \mathrm{wk}$ after transplantation, the recipients received six doses of Poly I:C. (P) Percentage of donor-derived CD45.2+ cells in the BM of recipient mice: LSK, LK, HSC, MPP, HPC-1, HPC-1 and differentiated cell lineages (Granulocytes, Monocytes and $B$ cells). $n=15-21$ recipients per genotype. $\mathrm{n}=3-4$ donors per genotype. All data are mean \pm SEM. ${ }^{*}, P$ $<0.05 ;{ }^{* *}, \mathrm{P}<0.01 ;{ }^{* * *}, \mathrm{P}<0.001{ }^{* * * *}, \mathrm{P}<0.0001$ (Mann-Whitney $\mathrm{U}$ test).

Figure 2. Haematopoiesis-specific deletion of PADI4 has no major impact on $B M$ reconstitution potential following haematopoietic injury and does not cause haematopoietic stem cell exhaustion in ageing mice. (A) Experimental design of haematopoietic injury approach. Padi $4^{\mathrm{CTL}}$ and Padi4 ${ }^{\mathrm{CKO}}$ mice received a $3 \mathrm{x}$ 5 -FU injections at $150 \mathrm{mg} / \mathrm{kg} 10$ days apart and were analysed 10 days after the last administration. (B) Immunophenotypic analysis of Padi4 ${ }^{\mathrm{CTL}}$ and Padi4 ${ }^{\mathrm{CKO}}$ mice was 
performed 10 days after the final dose of 5-FU. Total number of cells in BM: WBC, LSK, and LK; HSC, MPP, HPC-1 and HPC-2 cells; myeloid, erythroid and lymphoid progenitor cells: CMP, GMP, MEP, CLP, Pre-GMP, Pre-MegE, MkP, Pre-CFU, CFUE, Pro-Ery; differentiated Granulocytes, Monocytes, B cells, Erythroid cells. Padi4 ${ }^{\mathrm{CTL}}$, $\mathrm{n}=21$; Padi4 ${ }^{\mathrm{CKO}}, \mathrm{n}=18$. (C, D) Assessment of Padi4 deletion on ageing of HSCs. (C) Immunophenotypic analysis in BM of Padi4 ${ }^{\mathrm{CTL}}$ and Padi4 ${ }^{\mathrm{CKO}}$ mice aged for 1 year. WBC, LSK, LK; HSC, MPP, HPC-1 and HPC-2 cells; myeloid, erythroid and lymphoid progenitor cells: CMP, GMP, MEP, CLP, Pre-GMP, Pre-MegE, MkP, PreCFU, CFU-E, Pro-Ery; differentiated Granulocytes, Monocytes, B cells, Erythroid cells. CFC assay with aged BM samples. Total number of cells in Spleen; WBC, Granulocytes, Monocytes, B cells, erythroid cells and T cells. Padi4 ${ }^{\mathrm{CTL}}, \mathrm{n}=9$; Padi4 ${ }^{\mathrm{CKO}}, \mathrm{n}=8$. (D) $200 \mathrm{CD} 45.2+\mathrm{BM}$ HSCs from 1 year old mice were transplanted to primary recipient mice and monitored for 24 weeks following which immunophenotypic analysis was performed on BM and spleen. Contribution of donor derived CD45.2+ cells to the Granulocyte, Monocyte, B cell and T cell population in PB. Padi4 ${ }^{\mathrm{CTL}}, \mathrm{n}=20 ;$ Padi4 $^{\mathrm{CKO}}, \mathrm{n}=16$. Percentage of donor-derived CD45.2+ cells in total BM, LSK, LK, HSC, MPP, HPC-1, HPC-1 and differentiated cell lineages (Granulocytes, Monocytes, B cells and erythroid cells). Contribution of donor-derived CD45.2+ cell population to total spleen WBC count and differentiated cell populations. Padi4 ${ }^{\mathrm{CTL}}, \mathrm{n}=17 ;$ Padi4 $^{\mathrm{CKO}}, \mathrm{n}=15.3$-4 donors were used per genotype. All data are mean \pm SEM. ${ }^{*}, \mathrm{P}<0.05$ (Mann-Whitney $\mathrm{U}$ test).

Supplementary Figure 1. Blood profiling of Padi4 ${ }^{\mathrm{CTL}}$ and Padi4 ${ }^{\mathrm{CKO}}$ mice. Automated cell counting of blood samples from 8-12 week old Padi4 ${ }^{\mathrm{CTL}}$ and Padi4 ${ }^{\mathrm{CKO}}$; WBC, RBC, HGB, HCT, MCV, MCH, MCHC and PLT counts. Padi4 ${ }^{\mathrm{CTL}}, \mathrm{n}=$ 8; Padi4 ${ }^{\mathrm{CKO}}, \mathrm{n}=6$. Data are mean \pm SEM. ${ }^{*}, \mathrm{P}<0.05 ;{ }^{* *}, \mathrm{P}<0.01 ;{ }^{* *}, \mathrm{P}<0.001$; $* * * *, P<0.0001$ (Mann-Whitney U test).

Supplementary Figure 2. Peripheral blood analysis of mice transplanted with Padi4 $^{\mathrm{CTL}}$ and Padi4 ${ }^{\mathrm{CKO}}$ bone marrow. Percentage of donor-derived CD $45.2+$ cells in $\mathrm{PB}$ and contribution of donor derived CD45.2+ cells to the Granulocyte, Monocyte, B cell and T cell population in PB. (A) Analysis of primary recipient mice. Padi ${ }^{\mathrm{CTL}}, \mathrm{n}=$ 36; Padi4 ${ }^{\mathrm{CKO}}, \mathrm{n}=34$. (B) Secondary recipient mice. Padi4 ${ }^{\mathrm{CTL}}, \mathrm{n}=21 ;$ Padi4 $^{\mathrm{CKO}}, \mathrm{n}=$ 22. Data are mean \pm SEM. *,$P<0.05 ;{ }^{* *}, P<0.01 ;{ }^{* * *}, P<0.001 ;{ }^{* * *}, P<0.0001$ (Mann-Whitney U test).

Supplementary Figure 3. Acute deletion of Padi4. (A) Deletion of Padi4 following Poly I:C treatment in Padi4 ${ }^{\mathrm{IKO}}$ BM. (B) Percentage of donor-derived CD45.2+ cells in $\mathrm{PB}$ and contribution of donor derived CD45.2+ cells to the Granulocyte, Monocyte, B cell and T cell population in PB of recipient mice, after acute deletion of Padi4. $n=$ 15-21 recipients per genotype. $n=3-4$ donors per genotype. Data are mean \pm SEM. ${ }^{*}, \mathrm{P}<0.05 ;{ }^{* *}, \mathrm{P}<0.01 ;{ }^{* * *}, \mathrm{P}<0.001 ;{ }^{* * * *}, \mathrm{P}<0.0001$ (Mann-Whitney $\mathrm{U}$ test).

Supplementary Figure 4. 5-FU treatment leads to depletion of all bone marrow cells compartments in Padi4 ${ }^{\mathrm{CTL}}$ mice. Immunophenotypic analysis of Padi4 ${ }^{\mathrm{CTL}}$ mice treated with 5-FU or PBS vehicle control, demonstrating efficiency of 5-FU treatment. Experimental setup described in Figure 2A. Analysis was performed 10 days after the final dose of 5-FU; total number of cells in BM; WBC, LSK, and LK, HSC, MPP, HPC-1 and HPC-2 cells, myeloid, erythroid and lymphoid progenitor cells; CMP, GMP, MEP, CLP, Pre-GMP, Pre-MegE, MkP, Pre-CFU, CFU-E, Pro-Ery, differentiated Granulocytes, Monocytes, B cells, Erythroid cells and total number of cells in Spleen; WBC, B cells, Granulocytes and Monocytes Padi4 ${ }^{\mathrm{CTL}}, \mathrm{n}=21$; 
Padi4 $^{\text {CKO }} \mathrm{n}=18$. Data are mean \pm SEM. *, $\mathrm{P}<0.05 ;{ }^{* *}, \mathrm{P}<0.01 ;{ }^{* * *}, \mathrm{P}<0.001 ;{ }^{* * * *}$, $\mathrm{P}<0.0001$ (Mann-Whitney U test).

Supplementary Figure 5. Peripheral blood analysis of mice transplanted with aged Padi4 ${ }^{\mathrm{CTL}}$ and Padi4 ${ }^{\mathrm{CKO}}$ bone marrow. 200 CD45.2+ BM HSCs from 1 year old mice were transplanted to primary recipient mice and monitored for 24 weeks following which immunophenotypic analysis was performed on BM and spleen. Percentage of donor-derived CD45.2+ cells in PB. Contribution of donor derived CD45.2+ cells to the Granulocyte, Monocyte, B cell and T cell population in PB. Padi4 ${ }^{\mathrm{CTL}}, \mathrm{n}=20 ;$ Padi4 ${ }^{\mathrm{CKO}}, \mathrm{n}=16$. Data are mean \pm SEM. ${ }^{*}, \mathrm{P}<0.05 ;{ }^{* *}, \mathrm{P}<0.01$; ${ }^{* * *}, \mathrm{P}<0.001 ;{ }^{* * *}, \mathrm{P}<0.0001$ (Mann-Whitney U test). 
bioRxiv preprint doi: https://doi.org/10.1101/2021.04.13.439513; this version posted April 14, 2021. The copyright holder for this preprint

(which was not certified by peer review) is the author/funder, who has granted bioRxiv a license to display the preprint in perpetuity. It is Figure 1A-G made available under aCC-BY-NC-ND 4.0 International license.

A

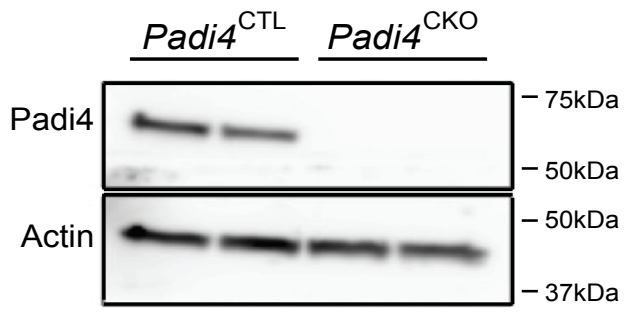

B

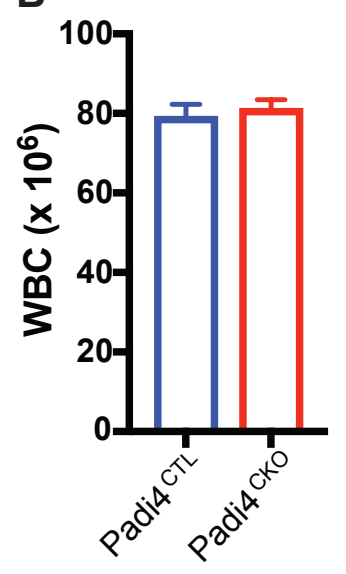

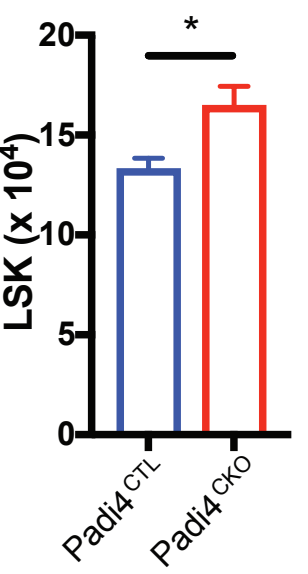

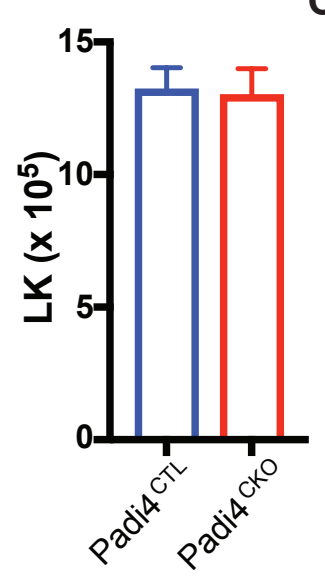

C

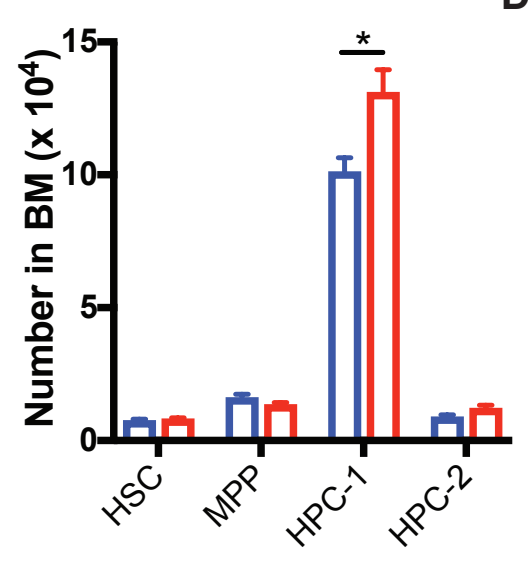

D

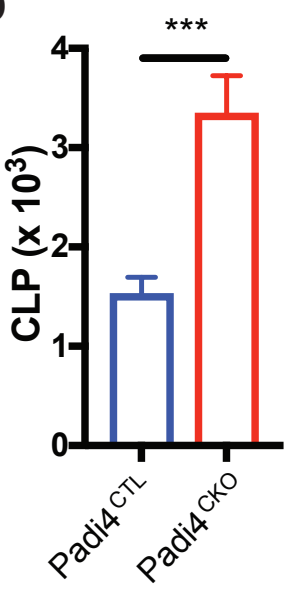

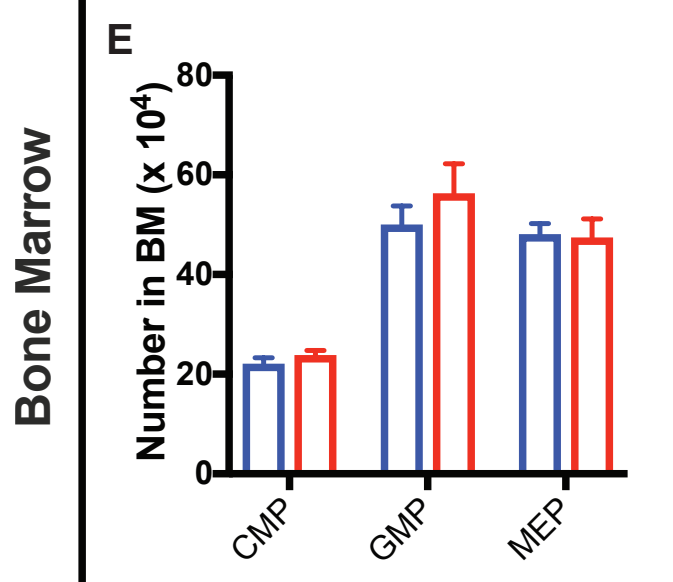
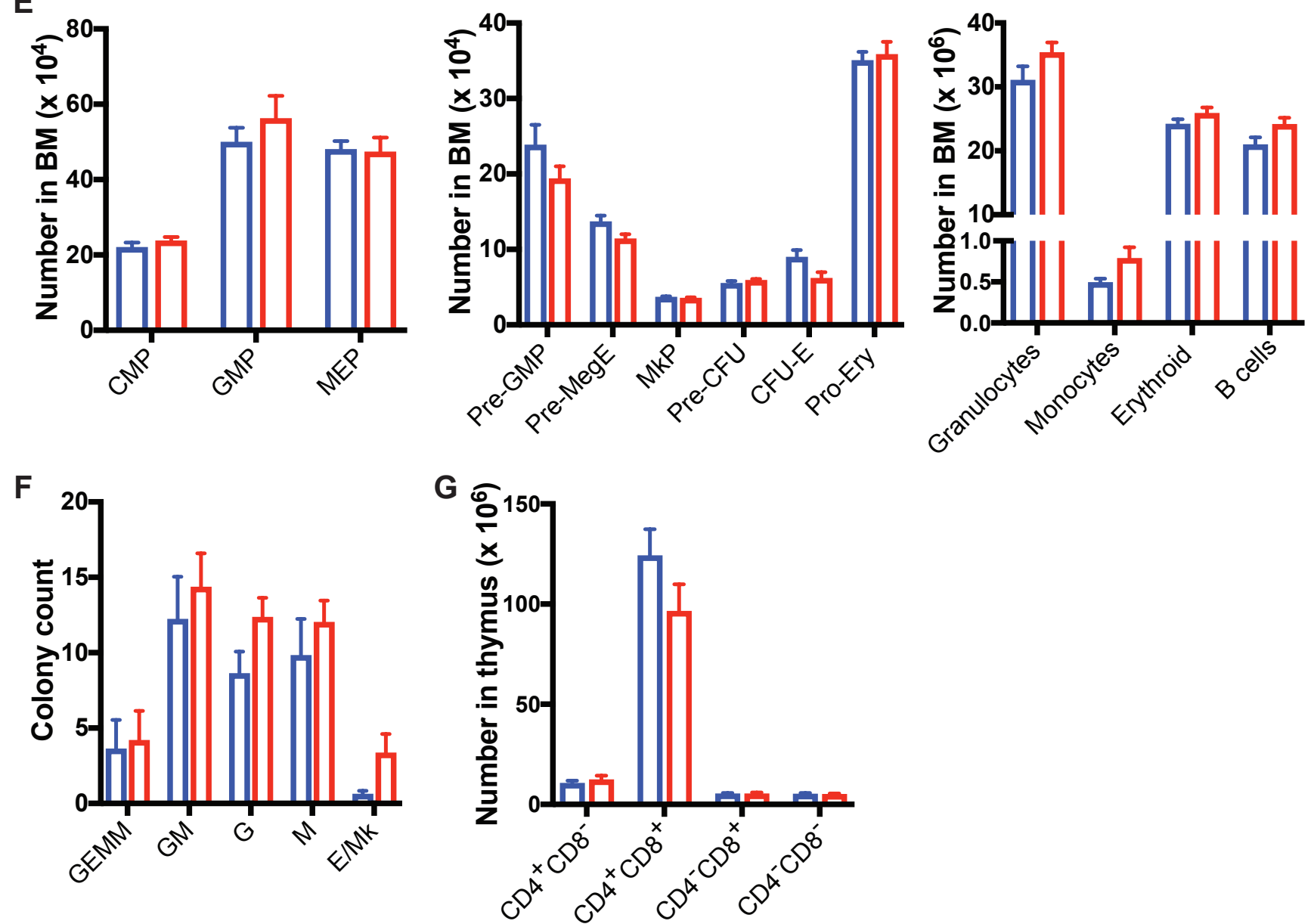

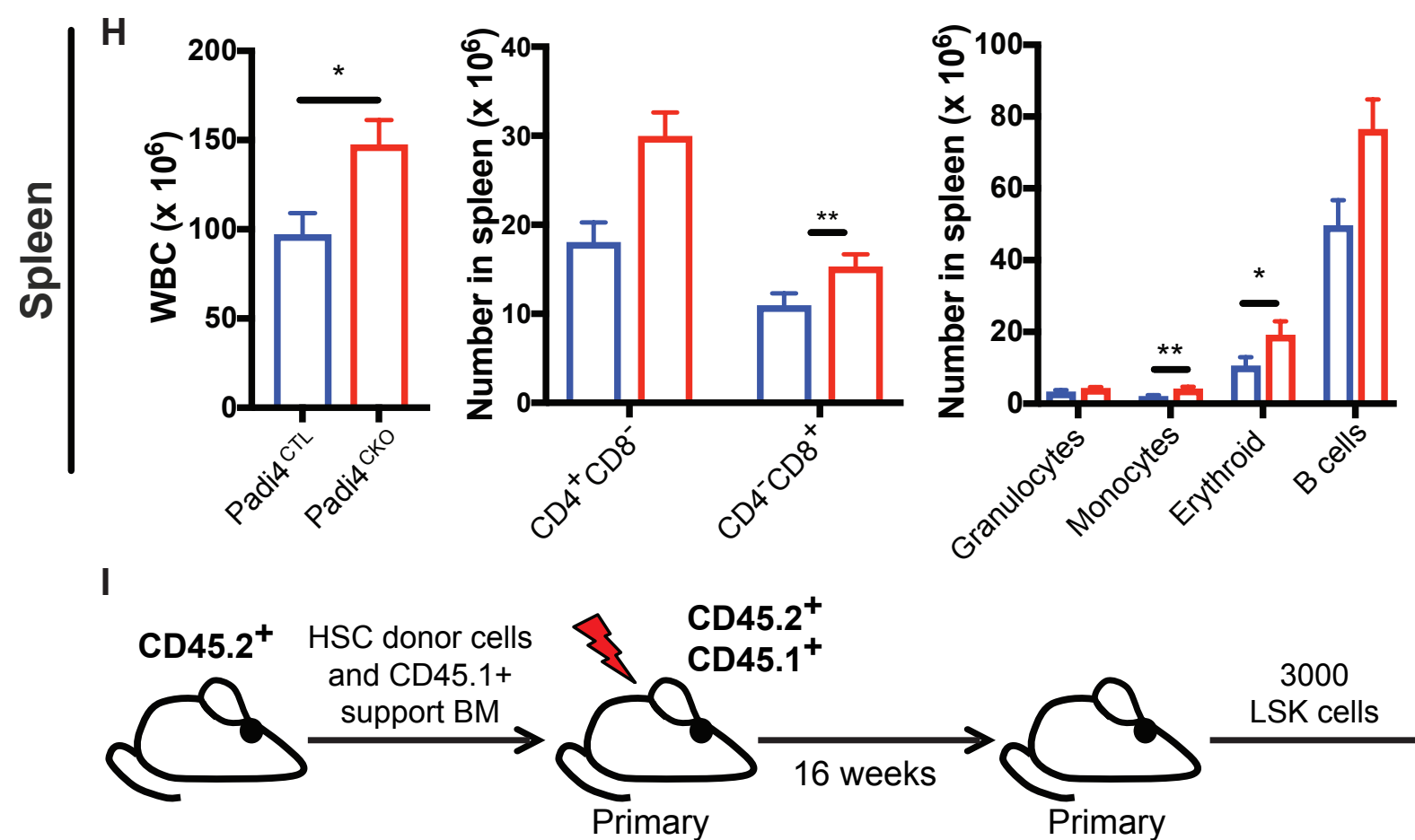

recipients
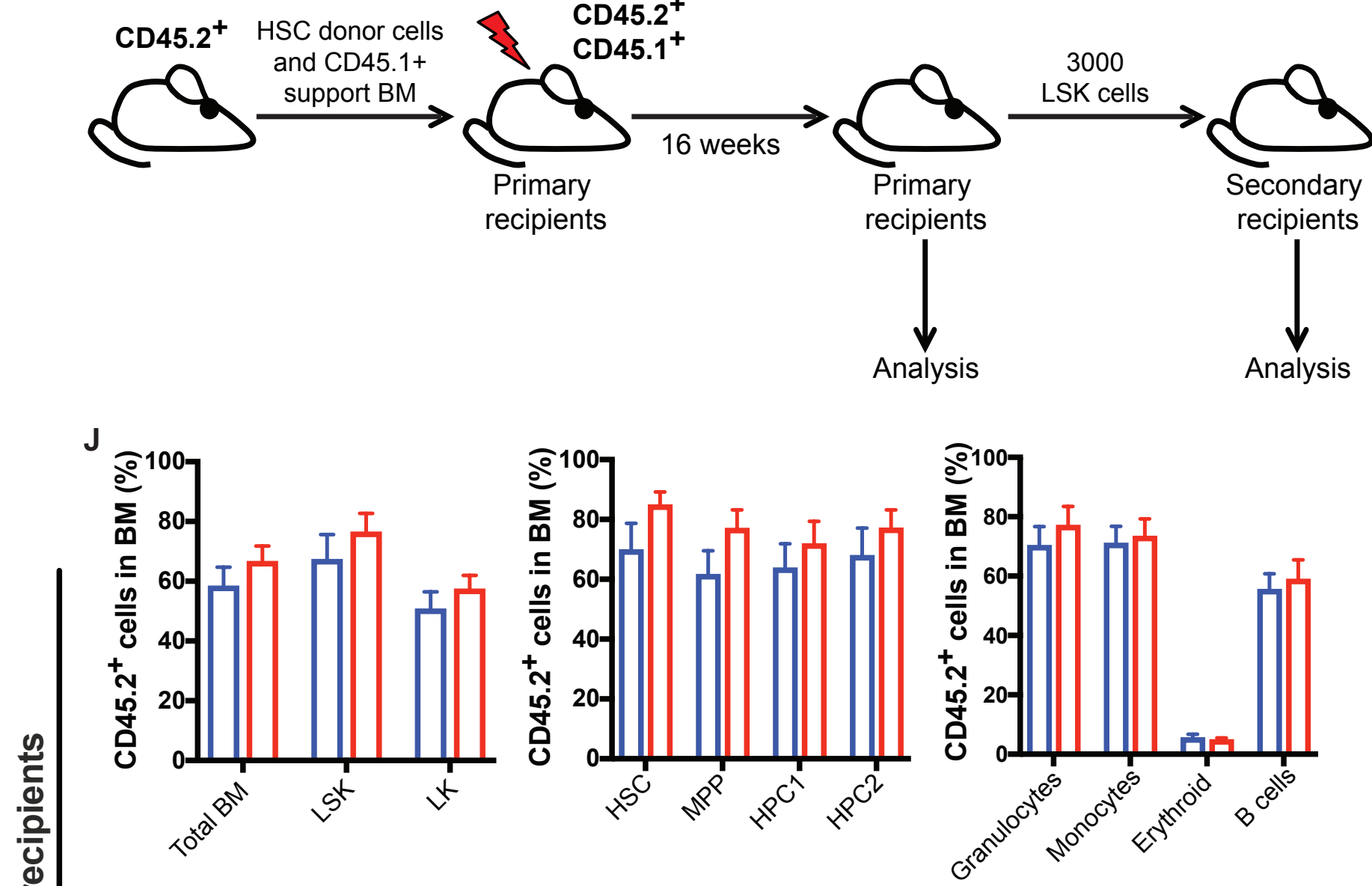

ํㅡㄹ
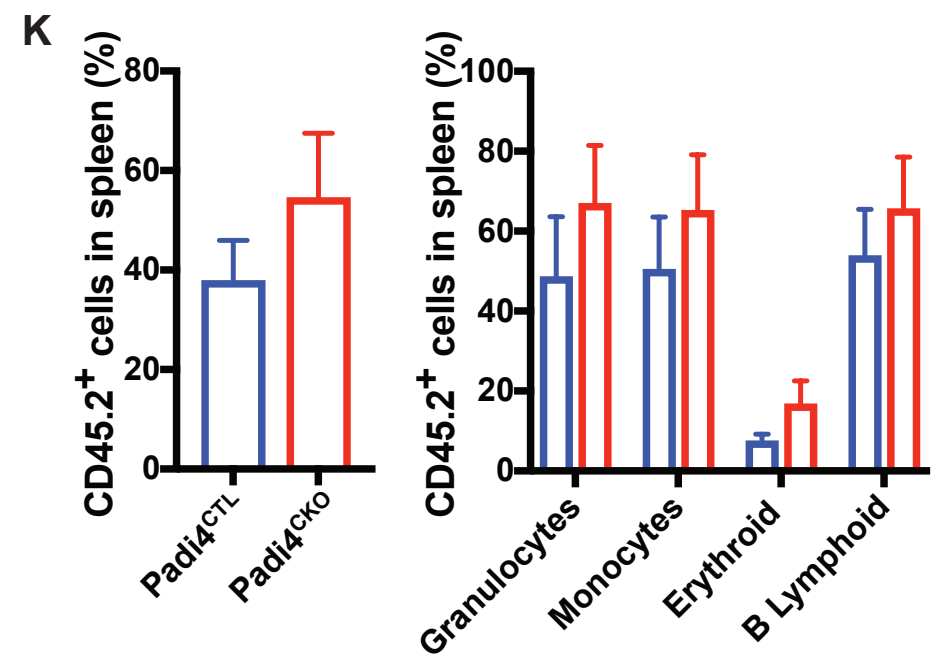

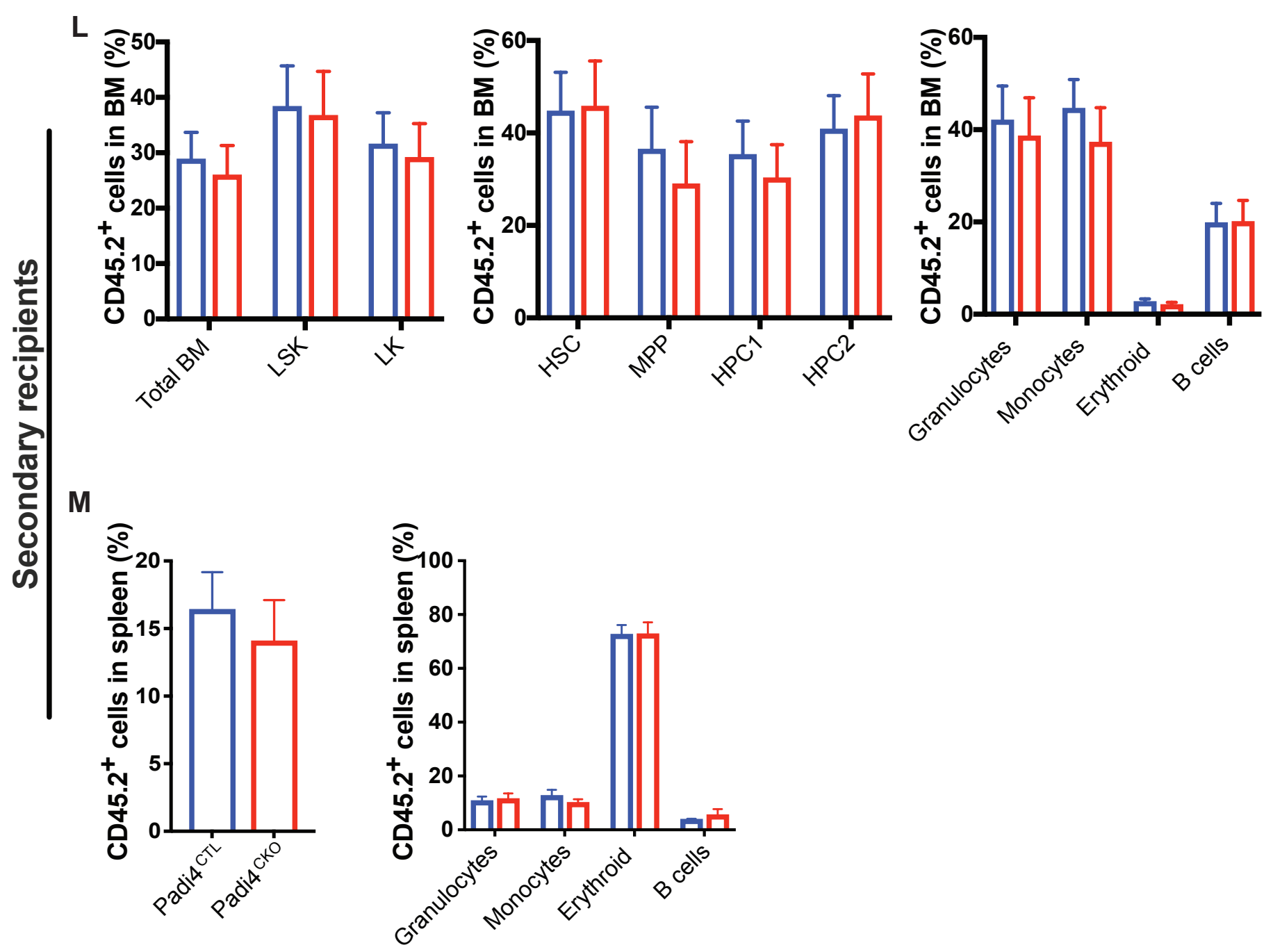
Figure 1N made available under aCC-BY-NC-ND 4.0 International license.

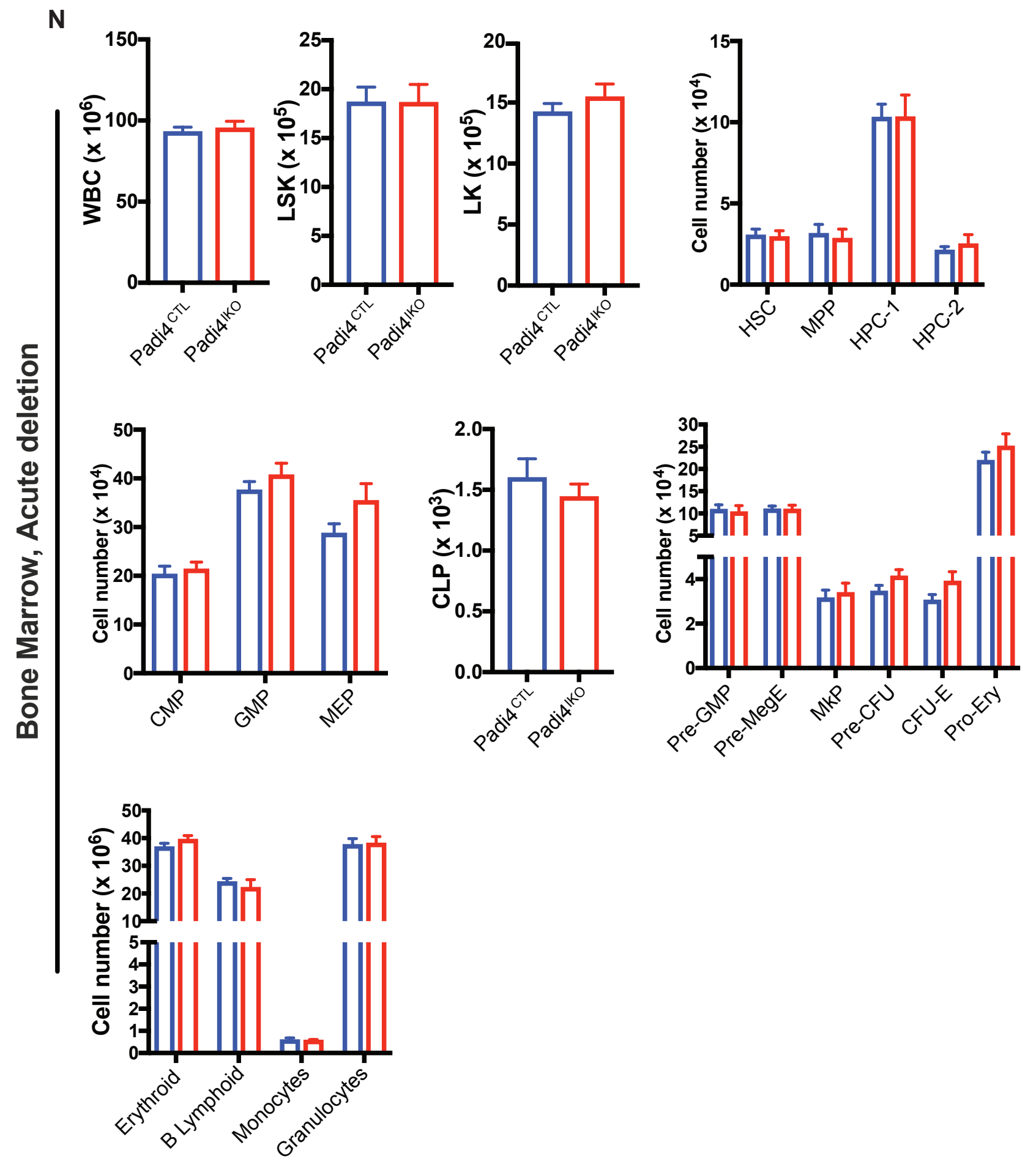


bioRxiv preprint doi: https://doi.org/10.1101/2021.04.13 439513; this version posted April 14, 2021. The copyright holder for this preprint (which was not certified by peer review) is the author/funder, who has granted bioRxiv a license to display the preprint in perpetuity. It is made available under aCC-BY-NC-ND 4.0 International license.

Figure 10-P

O
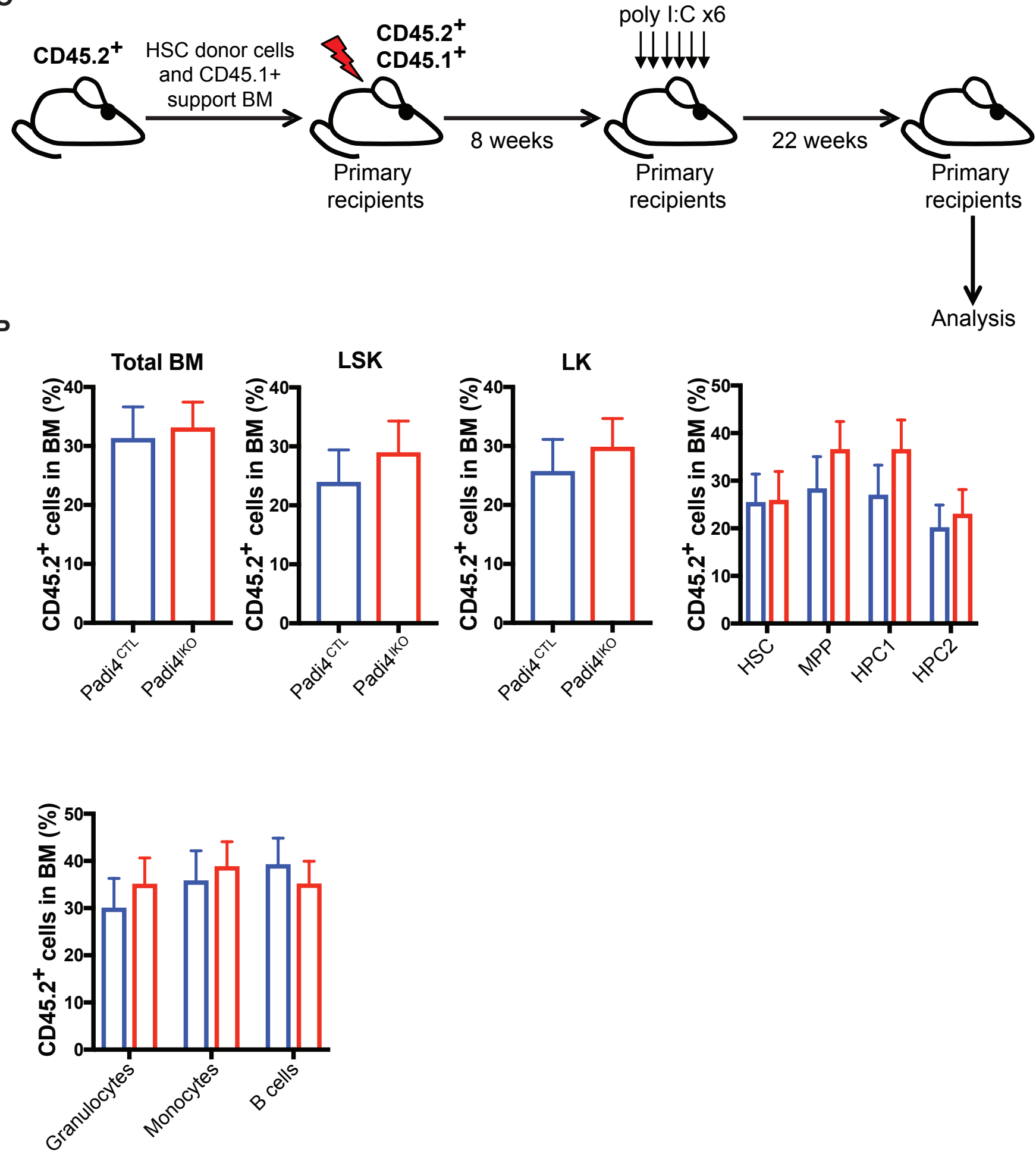